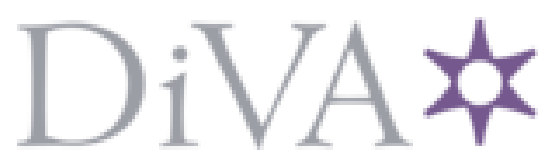

http://www.diva-portal.org

This is the published version of a paper published in Journal of Vacuum Science \& Technology. A. Vacuum, Surfaces, and Films.

Citation for the original published paper (version of record):

Mattsson, A., Hu, S-L., Hermansson, K., Österlund, L. (2014)

Infrared spectroscopy study of adsorption and photodecomposition of formic acid on reduced and defective rutile $\mathrm{TiO}_{2}$ (110) surfaces.

Journal of Vacuum Science \& Technology. A. Vacuum, Surfaces, and Films, 32(6): 061402

http://dx.doi.org/10.1116/1.4898568

Access to the published version may require subscription.

N.B. When citing this work, cite the original published paper.

Permanent link to this version:

http://urn.kb.se/resolve?urn=urn:nbn:se:uu:diva-227100 


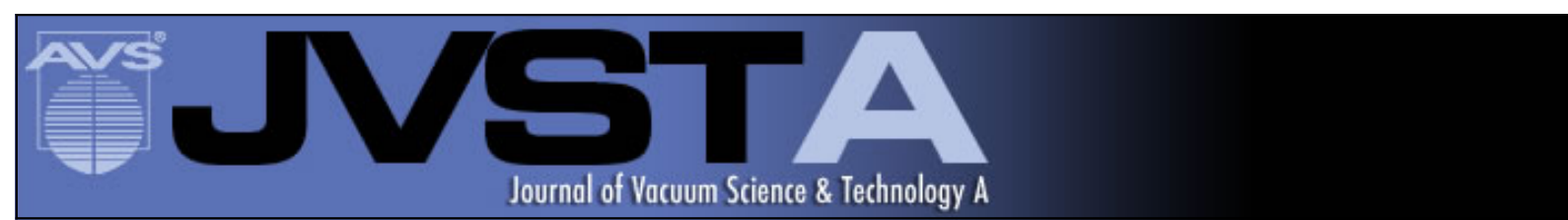

Infrared spectroscopy study of adsorption and photodecomposition of formic acid on reduced and defective rutile $\mathrm{TiO} 2(110)$ surfaces

Andreas Mattsson, Shuanglin Hu, Kersti Hermansson, and Lars Österlund

Citation: Journal of Vacuum Science \& Technology A 32, 061402 (2014); doi: 10.1116/1.4898568

View online: http://dx.doi.org/10.1116/1.4898568

View Table of Contents: http://scitation.aip.org/content/avs/journal/jvsta/32/6?ver=pdfcov

Published by the AVS: Science \& Technology of Materials, Interfaces, and Processing

\section{Articles you may be interested in}

The adsorption of a-cyanoacrylic acid on anatase TiO2 (101) and (001) surfaces: A density functional theory study

J. Chem. Phys. 141, 234705 (2014); 10.1063/1.4903790

Adsorption of formic acid on rutile TiO2 (110) revisited: An infrared reflection-absorption spectroscopy and density functional theory study

J. Chem. Phys. 140, 034705 (2014); 10.1063/1.4855176

Origin of enhanced water adsorption at $11^{-} 0$ step edge on rutile TiO2(110) surface

J. Chem. Phys. 137, 114707 (2012); 10.1063/1.4753951

Adsorption and thermal decomposition of acetic acid on $\mathrm{Si}$ ( 111 ) $7 \times 7$ studied by vibrational electron energy loss spectroscopy

J. Chem. Phys. 132, 174702 (2010); 10.1063/1.3400647

Adsorption of acetic and trifluoroacetic acid on the TiO 2 (110) surface

J. Chem. Phys. 121, 9039 (2004); 10.1063/1.1802652

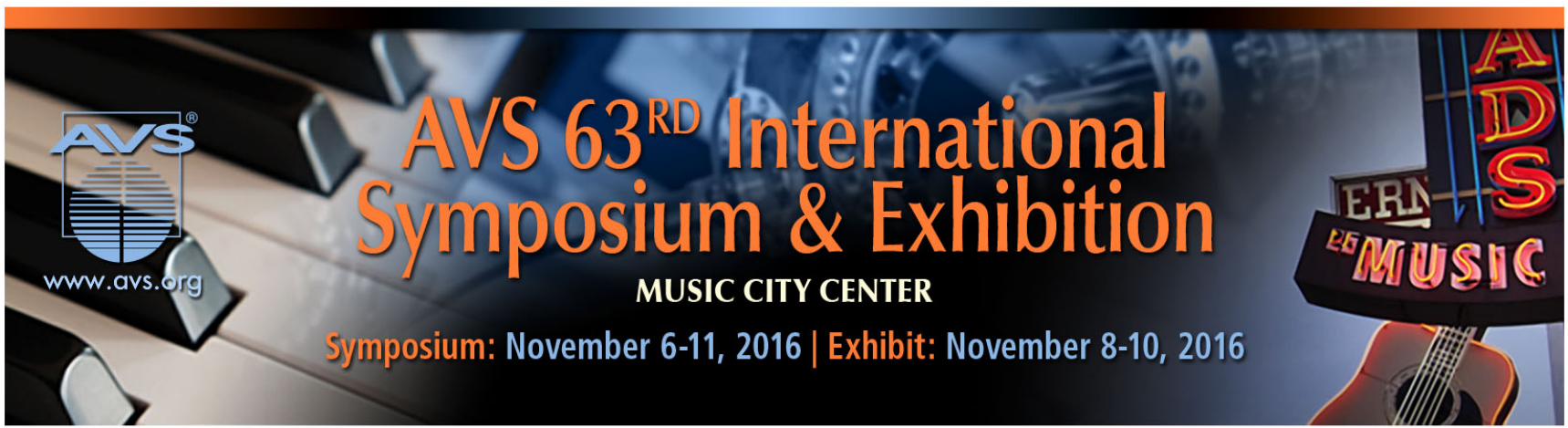




\title{
Infrared spectroscopy study of adsorption and photodecomposition of formic acid on reduced and defective rutile $\mathrm{TiO}_{2}(110)$ surfaces
}

\author{
Andreas Mattsson ${ }^{\text {a) }}$ \\ Department of Engineering Sciences, The Angström Laboratory, Uppsala University, P.O. Box 534, \\ SE-75121 Uppsala, Sweden \\ Shuanglin Hu and Kersti Hermansson \\ Department of Chemistry, The Angström Laboratory, Uppsala University, P.O. Box 538, \\ SE-75121 Uppsala, Sweden \\ Lars Österlund \\ Department of Engineering Sciences, The Angström Laboratory, Uppsala University, P.O. Box 534, \\ SE-75121 Uppsala, Sweden
}

(Received 8 July 2014; accepted 3 October 2014; published 24 October 2014)

\begin{abstract}
Adsorption and photodecomposition of formic acid on rutile $\mathrm{TiO}_{2}$ (110) have been investigated with infrared reflection-absorption spectroscopy (IRRAS) employing p- and s-polarized light along the [001] and [1 $1 \overline{0}$ ] crystal directions. The single crystal surfaces were prepared either by sputtering and annealing in ultrahigh vacuum (UHV) to obtain a reduced surface $\left(\mathrm{r}-\mathrm{TiO}_{2}\right)$, or by sputtering without annealing to create a rough, highly defective surface $\left(\mathrm{sp}-\mathrm{TiO}_{2}\right)$. Results are compared with corresponding measurements on rutile nanocrystals performed in synthetic air. IRRAS spectra obtained on $\mathrm{r}-\mathrm{TiO}_{2}$ and rutile nanocrystals are very similar, and show that in both cases formic acid dissociates and is predominately adsorbed as a bridging bidentate formate species, and that the formate adsorption structure on the nanocrystals is dominated by interactions with majority (110) surfaces. In contrast, the IRRAS spectra on $\mathrm{sp}-\mathrm{TiO}_{2}$ are different, with only minor spectral features associated with (110) surfaces and lost azimuthal symmetry, both of which imply changed adsorption geometry due to bonding to low-coordinated Ti atoms with lower valences. The UV-induced rate of formate photodecomposition is about 30 times higher on rutile nanocrystals in synthetic air compared with sp- $\mathrm{TiO}_{2}$ under UHV conditions, and even larger than on $\mathrm{r}-\mathrm{TiO}_{2}$. These differences are explained by the lack of oxygen and limited hydroxyl coverage under UHV conditions. The difference in reactivity between the $\mathrm{r}-\mathrm{TiO}_{2}$ and $\mathrm{sp}-\mathrm{TiO}_{2}$ surfaces is attributed to a high concentration of strongly bonded bridging bidentate formate species on the (110) surface, which lowers its reactivity. The results point to a pressure gap where the availability of molecular oxygen and the hydroxyl concentration limit the photoreactivity in UHV leading to an almost 20-fold decrease of the formate degradation rate in UHV. In contrast, the structure represented by the single crystal (110) surface is shown to capture the essential structural properties, which dictates the formic acid adsorption and adsorption structure of rutile nanocrystals. (C) 2014 American Vacuum Society.
\end{abstract}

[http://dx.doi.org/10.1116/1.4898568]

\section{INTRODUCTION}

Titanium dioxide $\left(\mathrm{TiO}_{2}\right)$ photocatalysis has over the past 40 years matured into a large research field, which is driven by its many applications in, e.g., photocatalytic air and water cleaning, ${ }^{1-3}$ photocatalytic water splitting, and hydrogen production. ${ }^{4-6}$ It is of utmost importance to unveil the elementary surface processes in these photocatalytic reactions in order to make further progress in this burgeoning research area. Recently, surface science studies have shed light on key molecular processes occurring on $\mathrm{TiO}_{2}$, employing a variety of surface science techniques, such as electron energy loss spectroscopy, low energy electron diffraction (LEED), photoelectron diffraction, scanning tunneling microscopy (STM), temperature programmed desorption, and combinations of them. ${ }^{7-11}$ From such studies the role of surface structure, surface defects, molecular oxygen, hydroxyls, and

${ }^{a)}$ Electronic mail: andreas.mattsson@angstrom.uu.se adsorbed water have been explored. Hitherto, most of these surface science studies have been conducted on the rutile $\mathrm{TiO}_{2}$ (110) surface, which represents the thermodynamically most stable surface of the rutile phase, and is readily available as large single crystals for a variety of experiments. ${ }^{9,10}$

Grazing incidence infrared reflection-absorption spectroscopy (IRRAS) has been used in a few studies to study adsorbate structures on $\mathrm{TiO}_{2}{ }^{12-19}$ IRRAS has the advantage of being surface sensitive and capable of identifying adsorbed molecular species and their coordination, based on their unique fingerprint spectra, using different polarizations of the IR light and crystal orientations. In general, one distinguishes between measurements on metal and semiconductor surfaces. For semiconductor surfaces, the adsorbate layer will act as a reflecting coating for the tangential electrical fields, which is not the case for metal surfaces, since the selection rules are different for the two types of surfaces. Thus, the denotation external reflection is normally used for semiconductor surfaces and reflectionabsorption spectroscopy for metal surfaces. ${ }^{20}$ Here, we use, 
however, the nomenclature IRRAS because all related surface science studies on $\mathrm{TiO}_{2}$ single crystals we are aware of $^{12-14,16,18}$ have employed this notation.

Formic acid $(\mathrm{HCOOH})$, the simplest organic acid, is a suitable probe molecule to study carboxylate- $\mathrm{TiO}_{2}$ surface interactions. It is generally agreed that formic acid dissociates on rutile $\mathrm{TiO}_{2}$ at temperatures above $110 \mathrm{~K}$ under most experimental conditions $\left(\mathrm{HCOOH} \rightarrow \mathrm{HCOO}_{\mathrm{ad}}+\mathrm{H}_{\mathrm{ad}}\right)^{7,13,15,21-23}$ The majority of adsorbed formate ions bond through the two oxygen atoms to two $\mathrm{Ti}_{5 \mathrm{c}}$ atoms along the troughs in the [100] direction in a bridging bidentate fashion, thus creating a $(2 \times 1)$ overlayer on the rutile surface. ${ }^{7,15}$ Formate has also been reported to bind to oxygen vacancy sites in the $\mathrm{O}$ ridges along the [001] direction, whereby the O-C-O molecular plane is rotated into the [110] direction, ${ }^{13}$ or to adsorb as monodentate hydrogen bonded species oriented perpendicular to the [001] direction to protonated two-fold coordinated bridging $\mathrm{O}_{2 \mathrm{c}}$ atoms. ${ }^{15,24,25}$ Aizawa et al. ${ }^{26}$ also reported on another adsorption structure, where the formate binds to an $\mathrm{O}$ vacancy to form a monodentate structure.

Here, we report on an IRRAS study of $\mathrm{HCOOH}$ adsorption on rutile $\mathrm{TiO}_{2}$ (110) using different surface preparation methods, where we compare a reduced $\mathrm{TiO}_{2}$ (110) surface, a sputtered (disordered) single crystal $\mathrm{TiO}_{2}$ (110), and large rutile nanoparticles (NP). In addition, we present results of photon-induced decomposition of formate. This is to our knowledge the first study of photodecomposition of formic acid on single crystal $\mathrm{TiO}_{2}(110)$.

\section{EXPERIMENT}

The experimental set-up has been described in detail elsewhere. ${ }^{15}$ Briefly, it consists of a vacuum-pumped FTIR spectrometer (Bruker IFS66v/S) equipped with an external $\mathrm{HgCdTe}$ liquid nitrogen cooled detector connected to an UHV chamber via $\mathrm{KBr}$ windows thus allowing the entire beam path to be under vacuum. The incident angle of the IR light is $85^{\circ}$ with respect to the surface normal of the sample. A wire-grid polarizer (KRS-5, Specac Inc.) was used to change between s- and p-polarization of the incident light. IRRAS measurements were performed with $4 \mathrm{~cm}^{-1}$ resolution [except for $\mathrm{TiO}_{2}$ (110) with light incident in the [1 10 ] direction, where $8 \mathrm{~cm}^{-1}$ was used], and averaged over 1024 scans. A schematic set-up of the crystal and the orientation of the crystal with respect to the IR beam employed in the present study are shown in Fig. 1 .

A $20 \times 20 \mathrm{~mm}$ rutile $\mathrm{TiO}_{2}$ (110) single crystal (PI Kem Ltd.) was used. The crystal was mounted in the UHV chamber as delivered and cleaned by repeated Argon ion sputtering $(1 \mu \mathrm{A}$ ion current at $1 \mathrm{keV}$ for $10 \mathrm{~min}$ at $323 \mathrm{~K}$ ) and annealing cycles $(973 \mathrm{~K}$ for $20 \mathrm{~min}),{ }^{7,10,15,27,28}$ which resulted in a reduced crystal (denoted $\mathrm{r}-\mathrm{TiO}_{2}$ ) that has been reported to have a $\mathrm{O}$ vacancy surface coverage of the order $\theta \approx 0.05$. $^{7,27,29}$ A rough surface was also prepared, where the final annealing cycle was omitted (denoted $\mathrm{sp}-\mathrm{TiO}_{2}$ ). The sputtering and annealing cycles were repeated four times before each IRRAS measurement. The LEED pattern was regularly checked, and for the reduced surface $\left(\mathrm{r}-\mathrm{TiO}_{2}\right)$, the typical $1 \times 1$ surface was
(110) surface

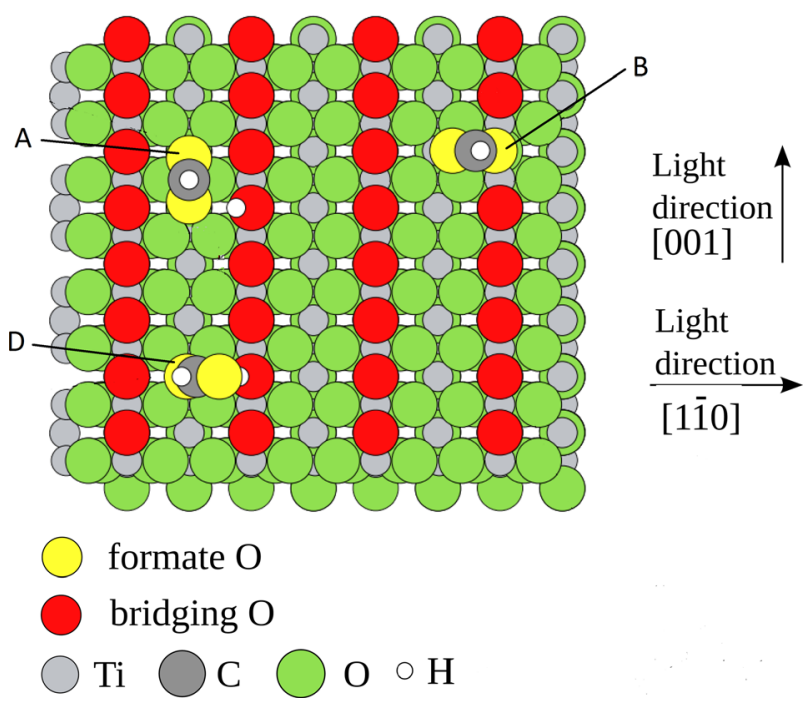

FIG. 1. (Color online) Schematic picture of the rutile $\mathrm{TiO}_{2}$ (110) surface with adsorbed formate molecules. One formate species is absorbed along the troughs in the [001] direction (majority species A), one species is adsorbed to a bridging oxygen vacancy (minority species B) and one species is adsorbed via a protonated bridging oxygen atom (minority species D). Also shown is the incoming direction for the IR light for the different azimuth angles, $\phi=0^{\circ}$ ([1ㅣㅣ $]$ direction) and $\phi=90^{\circ}$ ([001] direction) employed in the experiments.

observed. For sp- $\mathrm{TiO}_{2}$ no LEED pattern was discerned (beam voltage 50-150 V), indicating a disordered surface layer. Prior to the formic acid exposure the sample was flashed to $600 \mathrm{~K}$ in order to obtain a surface as hydroxyl free as possible. ${ }^{27}$ Exposure of the formic acid (puriss, Fluka) was made with a directed gas doser equipped with a $1 \mu \mathrm{m}$ pinhole connected to a formic acid reservoir placed in front of the sample. Before dosing the $\mathrm{HCOOH}$ gas lines and reservoir were subjected to several freeze-thaw cycles to remove impurities. The $\mathrm{HCOOH}$ dosing time was $60 \mathrm{~s}$, followed by a $60 \mathrm{~s}$ evacuation time prior to IRRAS measurements. This dosage time yields a formic acid coverage of approximately 1 monolayer. ${ }^{15}$

UV irradiation of the samples was done using the $365 \mathrm{~nm}$ emission line from a $\mathrm{Hg}(\mathrm{Xe})$ lamp (Oriel Instruments) in combination with a narrow band pass filter (Oriel Instruments, FWHM $=10 \mathrm{~nm}$ ). A water filter was used to remove the IR part of the radiation. The light was directed on the sample via a planoconvex quartz lens $(f=200 \mathrm{~mm})$ through a quartz viewport (Allectra) mounted on the UHV chamber. The distance between the lens and the sample is $450 \mathrm{~mm}$. The distance between the quartz window and the sample was $175 \mathrm{~mm}$, and the incident angle $40^{\circ}$. The incident light flux in the focal plane was $34 \mathrm{~mW} \mathrm{~cm}^{-2}$ as measured by a thermophile detector (Ophir), yielding an upper limit of the estimated flux at the sample surface of $2 \mathrm{~mW} \mathrm{~cm}^{-2}$.

\section{RESULTS AND DISCUSSION}

\section{A. Adsorption of formic acid}

Figure 2 shows p- and s-polarized IRRAS spectra of formic acid adsorbed on $\mathrm{r}-\mathrm{TiO}_{2}$ and $\mathrm{sp}-\mathrm{TiO}_{2}$ surfaces. The spectra 

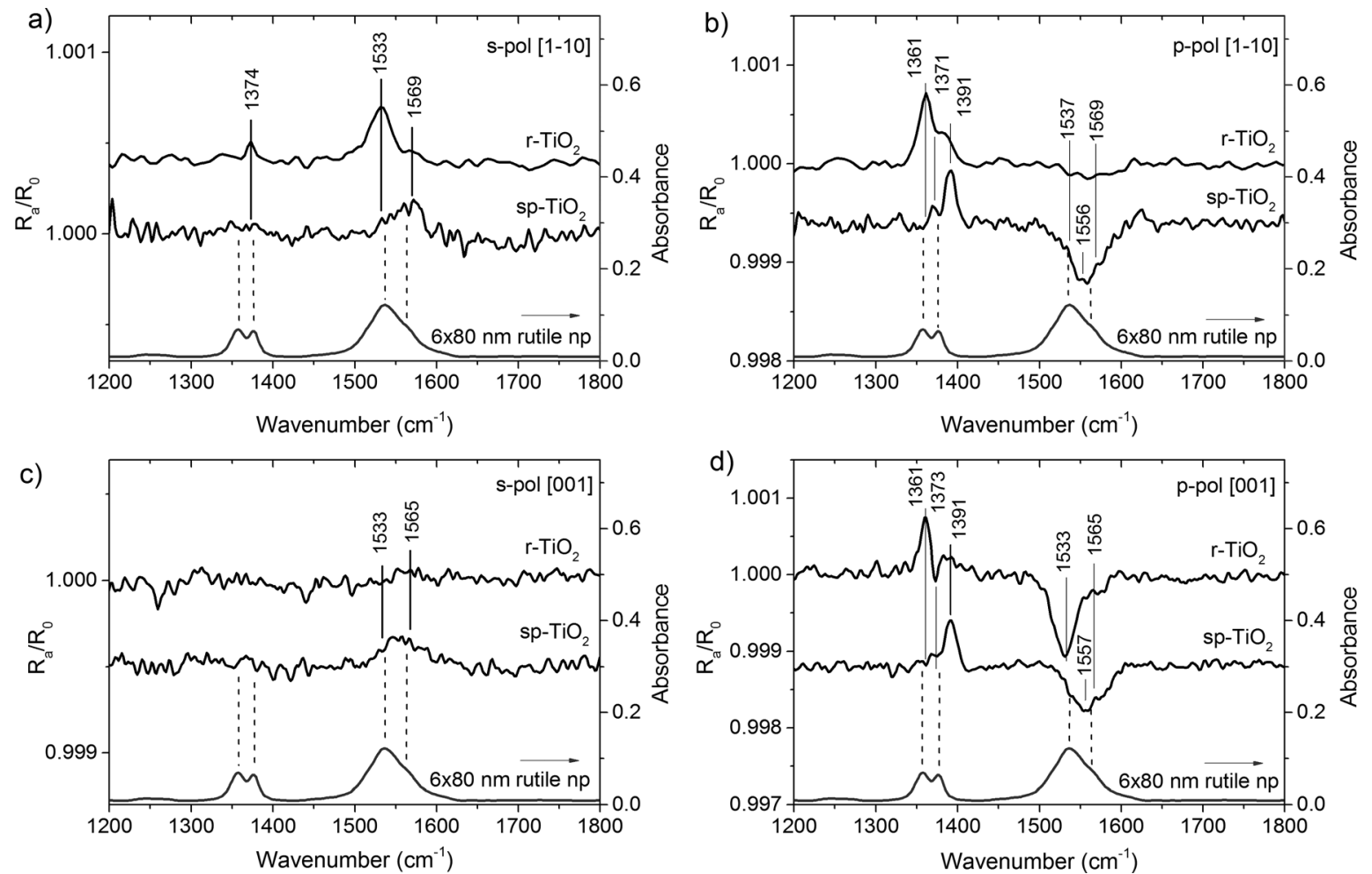

FIG. 2. IRRAS spectra of formate adsorbed on sputtered and reduced $\mathrm{TiO}_{2}(110)$ single crystal, as measured with s-polarized light [(a) and (c)], p-polarized light [(b) and (d)], and the IR beam incident in the [110] direction [(a) and (b)], and the [001] direction [(c) and (d)]. For comparisons, DRIFT spectra of formate adsorbed on rutile nanoparticle $(6 \times 80 \mathrm{~nm})$ acquired in synthetic air at atmospheric pressures is also shown at the bottom of each graph (adapted from Ref. 32). The solid lines mark the positions of IRRAS peaks on single crystal $\mathrm{TiO}_{2}(110)$, while the dashed lines mark the positions of the peaks in the deconvoluted DRIFT spectra on the rutile NP at 1358, 1371, 1536, and $1562 \mathrm{~cm}^{-1}$.

show results for the [001] and [110] orientations of the incident IR light with respect to the azimuthal orientation of the $\mathrm{TiO}_{2}(110)$ crystal. In general, the signal to noise ratio (SNR) is small in grazing angle IRRAS measurements of submonolayer adsorbate coverages on dielectric substrates. ${ }^{12-15}$ The results presented here were based on IR spectra with SNR values $>7000$ and spectral rms values of the order $3 \times 10^{-5}$, which yielded reproducible, statistically significant spectral features and photoinduced variations. Due to the different coupling between the adsorbed molecule and the substrate both absorption and transmission peaks, i.e. both a decrease and an increase in reflectance, will be seen in the spectra for the same vibrational mode depending on the orientation of the electric field vector of the incident light. A detailed discussion about these aspects of IRRAS spectroscopy can be found in the review by Chabal, ${ }^{20}$ and for applications to the $\mathrm{TiO}_{2}$ system, the reader is referred to the study by Mattsson et al. ${ }^{15}$

The IRRAS spectra for the r- $\mathrm{TiO}_{2}$ surface shown in Fig. 2 agree well with previously reported IRRAS measurements. ${ }^{13,15}$ As a result of the orientation of the adsorbed formate molecules, the vibrational modes couple differently to the IR light depending on polarization and $\mathrm{TiO}_{2}$ crystal orientation. For instance, the asymmetric $\nu(\mathrm{OCO})$ stretching mode of the majority species becomes inactive for p-polarized light along the [1ํㅣㄹ direction, but is active for s-polarized light incident along the [110] direction. ${ }^{15}$ The absorption and transmission bands seen in the IRRAS spectra can be assigned to two different formate bonding configurations (Fig. 1). The majority species (denoted "A" in the literature) corresponds to bridging bidentate formate, i.e., the formate ion bonded through its two oxygen atoms to two neighboring $\mathrm{Ti}_{5 \mathrm{c}}$ atoms along the troughs in the [001] direction. In this configuration the asymmetric and symmetric $\nu(\mathrm{OCO})$ stretch, and the in plane $\delta(\mathrm{C}-\mathrm{H})$ wagging can be found at 1533,1361 , and $1373 \mathrm{~cm}^{-1}$, respectively. ${ }^{15}$ In addition, in a previous study a minority species (denoted species "D") has been identified, where formate is bonded to a $\mathrm{Ti}_{5 \mathrm{c}}$ atom and a protonated oxygen atom, or hydroxylated oxygen vacancy, with a characteristic asymmetric $\nu(\mathrm{OCO})$ stretch located at $\sim 1565 \mathrm{~cm}^{-1}{ }^{15}$ The existence of a bridging bidentate formate species (denoted "B" in the literature), which is bonded to one $\mathrm{Ti}_{5 \mathrm{c}}$ atom and one bridging oxygen vacancy cannot be excluded. However, as we previously have shown, the rapid healing of bridging oxygen vacancies under our experimental conditions makes the presence of such formate species less likely than species D at monolayer coverages. ${ }^{15}$ Our molecular dynamics simulations showed that adsorption of formic acid molecules mainly proceeds via a D adsorption geometry. ${ }^{30}$ Although the $\mathrm{D}$ species is predicted to have significantly lower adsorption energy than species $\mathrm{A}$ and $\mathrm{B},{ }^{15,30}$ it is proposed to exist at saturation coverage due to site blocking.

On the sp- $-\mathrm{TiO}_{2}$ surface the IRRAS spectra look different. A dominant band appears at $1556 \mathrm{~cm}^{-1}$, whereas the band at $1533 \mathrm{~cm}^{-1}$ almost has disappeared, and a new vibrational band at $1391 \mathrm{~cm}^{-1}$ develops. These results can be understood from the lack of ordering of the $\mathrm{sp}-\mathrm{TiO}_{2}$ surface, which 
prohibits formation of large coverages of formate bonded in the energetically favored configurations depicted in Fig. 1. The sp- $\mathrm{TiO}_{2}$ surface is also expected to contain $\mathrm{Ti}^{3+}$ ions, as a consequence of the preferential sputtering of oxygen atoms. In an earlier study by Yamaguchi et al., ${ }^{31}$ it was found by STM and AES that $\mathrm{Ar}^{+}$sputtering resulted in a rough surface with $\sim 2 \mathrm{~nm}$ protrusions, containing significant amounts of $\mathrm{Ti}^{3+}$ cations. As a result of the modified surface structure, two things happen. First, the orientation of the adsorbed formate molecules becomes random, and hence, the dependence of the crystal orientation with respect to the incident light is lost, as shown in Fig. 2. Second, the adsorption geometry of the formate molecule is expected to change. Instead of the majority species A seen on the ordered $\mathrm{r}-\mathrm{TiO}_{2}$ surface, the formate is expected to bond asymmetrically to $\mathrm{Ti}^{3+}$ sites created by $\mathrm{Ar}^{+}$sputtering. ${ }^{32}$ This change of adsorption geometry and coordination also affects the energy of the different vibrational bands, as can be seen in Fig. 2, where the appearance of the band at $1391 \mathrm{~cm}^{-1}$ and the shift of the $\nu_{\text {as }}(\mathrm{OCO})$ band to $1556 \mathrm{~cm}^{-1}$ are attributed to the changed bonding geometry of the formate molecule. As can be seen in Fig. 2, the sp- $\mathrm{TiO}_{2}$ surface still exhibits small vibrational bands similar to the $\mathrm{r}-\mathrm{TiO}_{2}$ surface, thus suggesting the existence of detectable domains of (110) planes.

Adsorption of the formic acid on $6 \times 80 \mathrm{~nm}$ rutile NP at atmospheric pressures results in four distinct peaks at 1358 , 1375,1536 , and $1562 \mathrm{~cm}^{-1}$ in the IR spectra. ${ }^{33}$ These bands are attributed to the $\nu_{\text {as }}(\mathrm{OCO})$ and $\nu_{\mathrm{s}}(\mathrm{OCO})$ modes due to species A (1536 and $1358 \mathrm{~cm}^{-1}$, respectively), and the $\nu_{\mathrm{as}}(\mathrm{OCO})$ at $1562 \mathrm{~cm}^{-1}$ due to a minority species. The peak at $1375 \mathrm{~cm}^{-1}$ is attributed to $\delta(\mathrm{C}-\mathrm{H})$ and the $\nu_{\mathrm{s}}(\mathrm{OCO})$ for the minority species. Overall, the IR spectra obtained on $\mathrm{r}-\mathrm{TiO}_{2}$ and the NP sample are very similar since both exhibit a large fraction of bidentate bridging formate (species A). This is expected based on the large fraction of the low surface energy (110) planes seen in transmission electron microscopy of the NP samples. ${ }^{33}$ The main difference is that the concentration of minority species is much larger on the NP sample. This is expected since the NP samples contain more defects and thus exhibit a larger amount of hydroxylated oxygen vacancies or protonated oxygen atoms on the surface. The relatively large appearance of the majority species on the rutile NP means that the formic acid displaces water and hydroxyl groups on the NP surface, which is attributed to the high heat of adsorption of formic acid on $\mathrm{TiO}_{2}(110) .{ }^{15}$ Thus, despite the fact that the measurements on the rutile NP is made at ambient conditions at atmospheric pressure, the IR spectra of formate resembles very closely that on a $\mathrm{TiO}_{2}(110)$ single crystal at UHV conditions. In contrast, the IR spectra of the NP and sp- $\mathrm{TiO}_{2}$ samples are very different. The main differences are the shift of the $\nu_{\text {as }}(\mathrm{OCO})$ band and the appearance of a band at $1391 \mathrm{~cm}^{-1}$, which is not seen on the NP sample. As discussed above, the top atomic layers of the $\mathrm{sp}-\mathrm{TiO}_{2}$ sample are disordered and contain a large number of low-coordinated atoms and $\mathrm{Ti}^{3+}$ cations, thereby promoting different formate bonding configurations compared with the $\mathrm{NP}$ and $\mathrm{r}-\mathrm{TiO}_{2}$ samples. We thus conclude that $\mathrm{r}-\mathrm{TiO}_{2}$ single crystal is an excellent model system to study well-crystallized rutile NP samples, and that $\mathrm{Ti}^{3+}$ cations, and edge defects, contribute little to the IR spectra of adsorbed formic acid on nanocrystalline rutile.

\section{B. Photodecomposition of formate}

In Fig. 3 is shown IRRAS spectra in the $1200-1500 \mathrm{~cm}^{-1}$ region for p-polarized IR light incident in the [110] and [001] direction for both $\mathrm{r}-\mathrm{TiO}_{2}$ and $\mathrm{sp}-\mathrm{TiO}_{2}$, before and after
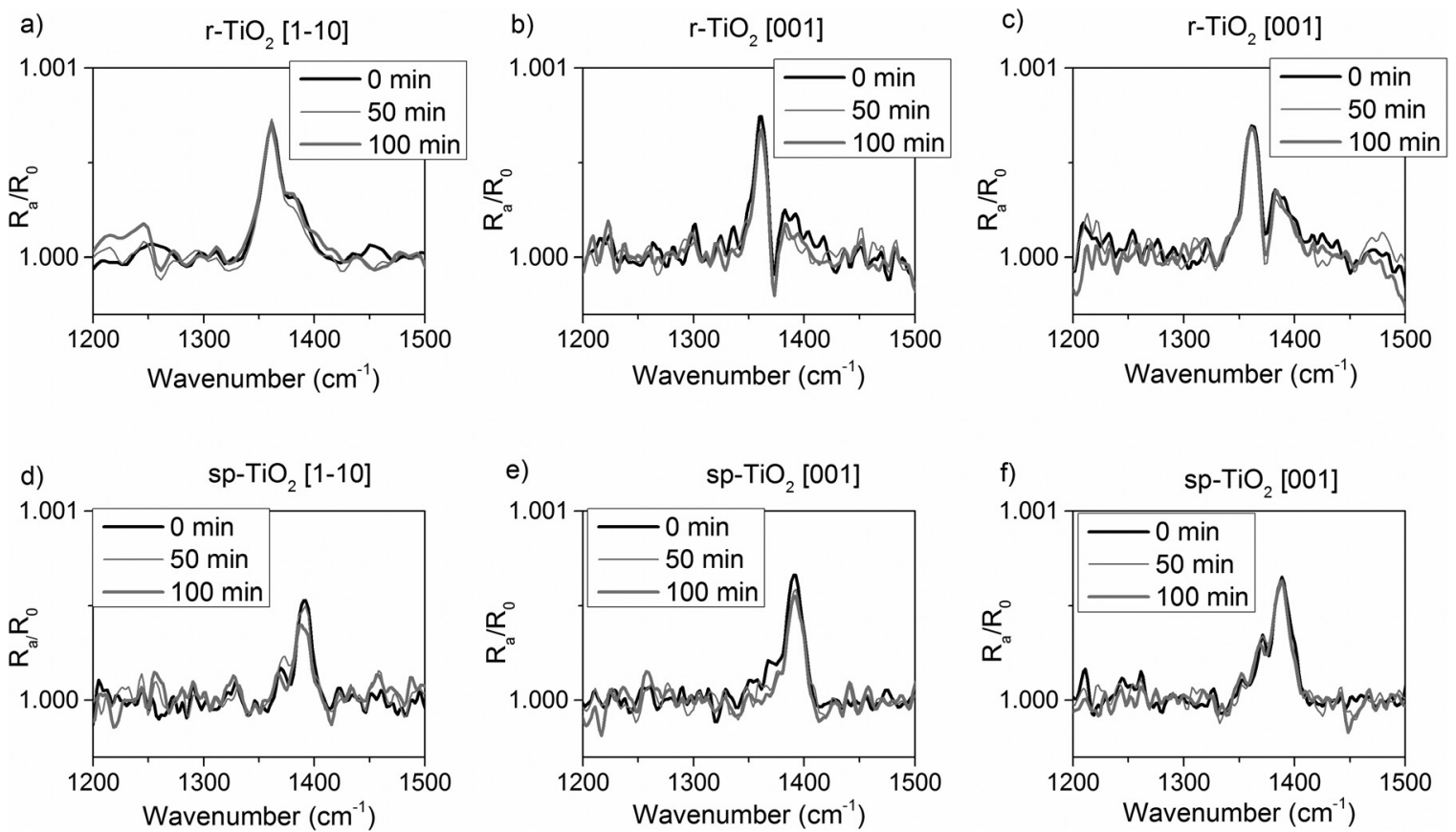

FIG. 3. IRRAS spectra before and after 50 and $100 \mathrm{~min}$ of UV irradiation of formic acid with p-polarized light incident in the [11̄0] direction [(a) and (d)] and in the [001] direction [(b) and (e)] for $\mathrm{r}-\mathrm{TiO}_{2}$ (upper row) and $\mathrm{sp}-\mathrm{TiO}_{2}$ (lower row). For comparisons, measurements without UV irradiation but same duration of the experiments are also shown for p-polarized light incident in the [001] direction on $\mathrm{r}-\mathrm{TiO}_{2}$ (c) and $\mathrm{sp}-\mathrm{TiO}_{2}$ (f). 

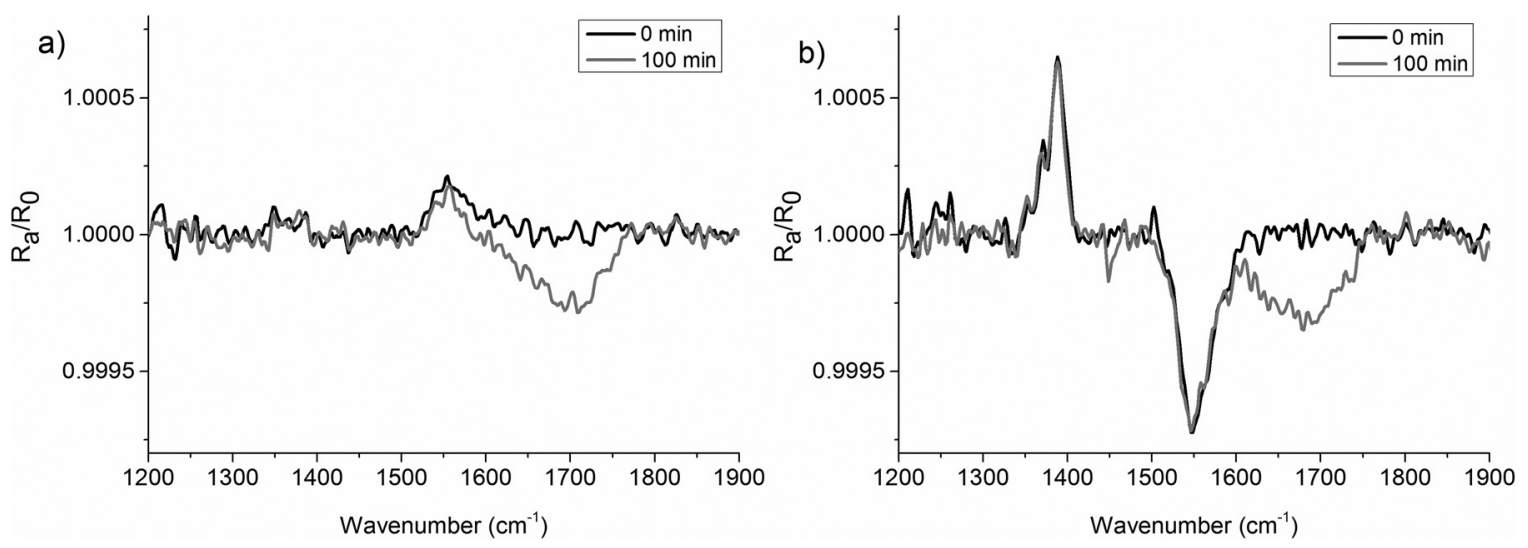

FIG. 4. IRRAS spectra directly after formic acid dosing, and after 100 min dwell time, measured with (a) s-polarized light incident in the [001] direction and (b) p-polarized light incident in the [001] direction on $\mathrm{r}-\mathrm{TiO}_{2}$.

100 min of irradiation. Due to slow formate photodecomposition reactions, long experimental times are required to follow the reaction under our experimental conditions. This introduces some additional experimental difficulties. As seen in Fig. 4, a broad absorption band due to the $\delta(\mathrm{HOH})$ band in water appears between 1650 and $1700 \mathrm{~cm}^{-1}$ in the IRRAS spectra after extended measurement times up to $100 \mathrm{~min}$ in dark (which is further confirmed by the appearance of $\nu(\mathrm{OH})$ stretching bands; data not shown). This band is seen as an absorption band in all measurements regardless of surface preparation and polarization of incident light. Since grazing angle s-polarized light always leads to emission bands for molecules adsorbed on the $\mathrm{TiO}_{2}$ surface, ${ }^{15,20}$ we can disregard the possibility that this is water condensing on the surface. This can primarily be assigned to condensation of water vapor on the LN2 cooled MCT detector chip. ${ }^{34}$ The appearance of this water band obscures, however, the $\nu_{\text {as }}(\mathrm{OCO})$ band and makes it difficult to quantify small changes of this band. The symmetric $\nu_{\mathrm{s}}(\mathrm{OCO})$ band was therefore chosen for quantification of formate photodecomposition.

In Fig. 3, a small decrease in peak amplitude of the symmetric $\nu(\mathrm{OCO})$ band is seen after 100 min UV irradiation. This small decrease is also discernible for s-polarized light (not shown). Comparisons of spectra recorded with [Figs. 3(a), 3(b), 3(d), and 3(e)] and without UV irradiation [Figs. 3(c) and 3(f)], but otherwise identical conditions, reveal that the peak amplitude of the $\nu_{\mathrm{s}}(\mathrm{OCO})$ bands decreases upon UV irradiation. Table I shows the relative changes of the $\nu_{\mathrm{a}}(\mathrm{OCO})$ band maxima. Figure 5 and Table I also shows the corresponding fit of the absorbance data to the photodecomposition of formic acid assuming first-order reaction kinetics employing the integrated absorbance for the symmetric $\nu_{\mathrm{s}}(\mathrm{OCO})$ and $\delta(\mathrm{C}-\mathrm{H})$ vibration with IR light incident along the [110] direction. It is clear that the observed photodecomposition after 100 min UV irradiation employing $2 \mathrm{~mW} \mathrm{~cm}{ }^{-2}$ is small. Nevertheless, it is clear that the rate of photodecomposition of formate is larger for the sp- $\mathrm{TiO}_{2}$ surface compared with the $\mathrm{r}-\mathrm{TiO}_{2}$ surface.

We have previously examined the possible adsorption structures of formic acid and formate on the $\mathrm{TiO}_{2}(110)$ surface, and performed a detailed vibrational mode assignment analysis of these structures. ${ }^{15}$ A close examination of our IR spectra recorded under UV illumination does not reveal any new vibrational bands. We therefore conclude that, within the levels of the SNR in our spectra, there is no photoinduced reorientation of formate on the surface into other energetically preferred adsorption structures, and that the measured decreases of the IR peak amplitudes in the spectra in Fig. 3 are due to photodecomposition of formate.

The decrease of the $\nu_{\mathrm{s}}(\mathrm{OCO})$ band on $\mathrm{r}-\mathrm{TiO}_{2}$ even after 100 min irradiation is too small to accurately perform a kinetic analysis of the decomposition reaction. However, employing longer experimental times introduces spectral changes due to IR absorption of shallow trap states, ${ }^{35}$ and changes in the IR beam transmission due to water condensation on the LN2 cooled MCT detector chip, which obscures the format IR bands, and thus prevent accurate determination of small absorbance variations. This can be compared with other studies of photodecomposition of formate on rutile

TABLE I. Relative change in peak amplitude of the $\nu_{\mathrm{s}}(\mathrm{OCO})$ band for $\mathrm{r}-\mathrm{TiO}_{2}$ and $\mathrm{sp}-\mathrm{TiO}_{2}$ after 100 min irradiation with $365 \mathrm{~nm} \mathrm{UV}$ irradiation $\left(\sim 2 \mathrm{~mW} \mathrm{~cm}{ }^{-2}\right)$ as well as the rate constant determined with a first-order kinetics relationship using the integrated symmetric $\nu_{\mathrm{s}}(\mathrm{OCO})$ and $\delta(\mathrm{C}-\mathrm{H})$ vibration with the IR light incident along the $[1 \overline{1} 0]$ direction for the single crystals.

\begin{tabular}{|c|c|c|c|c|c|c|c|}
\hline \multirow[b]{2}{*}{ Sample } & \multicolumn{3}{|c|}{$\mathrm{r}-\mathrm{TiO}_{2}$} & \multicolumn{3}{|c|}{$\mathrm{Sp}-\mathrm{TiO}_{2}$} & \multirow{2}{*}{ Rutile $\mathrm{TiO}_{2}$ nanoparticles } \\
\hline & {$[1 \overline{1} 0]$} & {$[001]$} & [001] no UV & {$[1 \overline{1} 0]$} & {$[001]$} & [001] no UV & \\
\hline Relative change $\left(\times 10^{-5}\right)$ & -0.03 & -0.08 & -0.04 & -0.21 & -0.17 & -0.03 & \\
\hline$k_{\mathrm{dec}}\left(\times 10^{-4}\right)\left(\mathrm{min}^{-1}\right)$ & n.a. & n.a. & - & 9 & & - & 20 \\
\hline$K_{\mathrm{dec}}\left(\times 10^{-19}\right)\left(\mathrm{min}^{-1}\right.$ photon $\left.^{-1} \mathrm{~s}^{-1}\right)$ & n.a. & n.a. & - & $6 \times 10^{-2}$ & & - & 2 \\
\hline
\end{tabular}




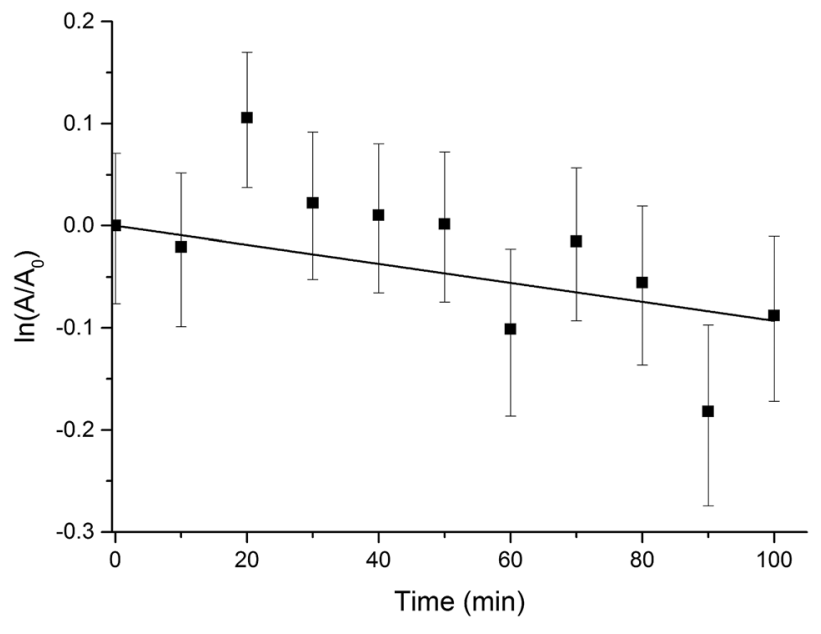

FIG. 5. First order fit of the photodecomposition of formic acid dosing adsorbed on the sp- $\mathrm{TiO}_{2}$ surface with the IR light incident along the [1] 0 ] direction, using the symmetric $\nu_{\mathrm{s}}(\mathrm{OCO})$ and $\delta(\mathrm{C}-\mathrm{H})$ vibration. The error bars are determined using the RMS value of the noise in the spectra. For each spectrum, the noise RMS value is multiplied by the wavenumber range over which the peak integration is made in order to get an estimate of the error in peak area. Thereby, the maximum and minimum peak area can be determined and thus also the deviation of $\ln \left(\mathrm{A} / \mathrm{A}_{0}\right)$.

nanoparticles, under atmospheric conditions, where very small decomposition rates was observed. ${ }^{33}$ For large rutile nanoparticles $(6 \times 80 \mathrm{~nm})$, the formate decomposition rate was determined to be $0.002 \mathrm{~min}^{-1}$ in synthetic air. ${ }^{33}$ Scaling this with the number of incident photons per second (with $\mathrm{h} \nu>$ band gap energy), $\sim 1 \times 10^{16}$ photons $\mathrm{s}^{-1}$, as determined from the spectral irradiance of the lamp, the power incidence on the sample and the size of the sample area, ${ }^{33}$ the decomposition rate of formic acid per photon is then about $2 \times 10^{-19} \mathrm{~min}^{-1}$ photon $^{-1} \mathrm{~s}^{-1}$ on the rutile nanoparticles.

Applying a first-order reaction kinetics analysis, $A(t)$ $=A_{0} e^{-k t}$, to the integrated peak area at $1380 \mathrm{~cm}^{-1}$ (attributed to both the symmetric $\nu_{\mathrm{s}}(\mathrm{OCO})$ and the $\delta(\mathrm{C}-\mathrm{H})$ vibration on sp- $\left.\mathrm{TiO}_{2}\right)$, where $A(t)=1-R_{a}(t) / R_{0}$ is the absorbance, the rate constant, $k_{\mathrm{dec}}$, is calculated to be $k_{\mathrm{dec}}=(9 \pm 3) \times 10^{-4} \mathrm{~min}^{-1}$, using data for the $\mathrm{sp}-\mathrm{TiO}_{2}$ surface along the [110] azimuth (Fig. 5). Using the number of incident photons $\left(\sim 2 \times 10^{17} \mathrm{~s}^{-1}\right)$, determined from the measured irradiance for the $\mathrm{Hg}$ lamp, the $365 \mathrm{~nm}$ bandpass filter transmission, the quartz window transmission characteristics from the supplier, and the sample size, we obtain a photodecomposition rate of $K_{\mathrm{dec}}=(6 \pm 2) \times 10^{-21} \mathrm{~min}^{-1}$ photons ${ }^{-1} \mathrm{~s}^{-1}$. This rate is about a factor of 30 lower than that for the rutile nanoparticles. This large difference in $K_{\mathrm{dec}}$ can qualitatively be understood as follows: Oxidation of formate proceeds primarily by reactions with $\mathrm{OH}$ radicals; direct hole interaction with formate is believed to be less important. ${ }^{9}$ Even under UHV conditions adsorption of small amounts of water from the background is inevitable, and a low coverage of adsorbed $\mathrm{OH}$ groups gradually develops in the course of the IRRAS measurement time. ${ }^{15,27}$ The $\mathrm{OH}$ radicals are formed by charge transfer of electrons from hydroxyl groups to the holes in the valence band of the photoexcited $\mathrm{TiO}_{2}$. ${ }^{1}$ The presence of hydroxyl groups on the surface is therefore crucial. Reaction between photogenerated $\mathrm{OH}$ radicals and formate then accounts for the observed photodecomposition evident in Fig. 3 and Table I. The $\mathrm{OH}$ source cannot however be replenished in UHV to sustain the reaction. Studies of the photodecomposition of acetic acid and acetone on $\mathrm{TiO}_{2}$ nanoparticles in inert atmosphere, i.e., where oxygen is intentionally removed from the reaction gas, show that lattice oxygen is used for the photodecomposition of the adsorbed species, and if there are no gas-phase oxygen available to replenish the lattice oxygen the decomposition rate becomes limited by the diffusion rate of oxygen atoms from the bulk of the $\mathrm{TiO}_{2}$ nanoparticles to the surface. ${ }^{36-38}$ In UHV conditions, there exist, however, virtually no oxygen molecules, which can act as electron scavenger, and hence suppress e-h pair recombination. Under UHV conditions, the photodecomposition rate will then be determined by reactions with the availability of surface hydroxyls and the rate of oxygen diffusion from the bulk. A gradual reduction of the surface region is therefore anticipated, which results in a decreasing degradation rate.

In contrast, on the $\mathrm{sp}-\mathrm{TiO}_{2}$ surface the photodecomposition rate is much larger than on the $\mathrm{r}-\mathrm{TiO}_{2}$ surface (Table I) despite that both surfaces are performed under UHV conditions. This discrepancy can be due to two reasons. First, as we have shown above, the coordination of a significant fraction of the adsorbed formate molecules is coordinated differently on $\mathrm{sp}-\mathrm{TiO}_{2}$ compared to $\mathrm{r}-\mathrm{TiO}_{2}$ (110) and the NP samples, which both are dominated by bridging bidentate formate (species A in Fig. 1). We have previously shown that the binding energy of those species is large in comparison with other types of formate adsorption structures. ${ }^{15}$ Second, the disordered $\mathrm{sp}-\mathrm{TiO}_{2}$ surface with a larger fraction of low-coordinated atoms is likely to bind more water and hydroxyls, and also facilitate lattice oxygen to participate in the photodecomposition reaction more easily.

It can thus be assumed that the presence of oxygen on the surface, either by diffusion from the bulk or from the surrounding atmosphere, affects the decomposition rate. This is manifested in the different degradation rates observed here with the lowest rate on $\mathrm{r}-\mathrm{TiO}_{2}$ and the highest rate on the rutile NP in ambient conditions. Thus, we conclude that a pressure gap exist, where the concentration of surface hydroxyls and oxygen becomes rate limiting in UHV.

\section{CONCLUSIONS}

Saturation coverage adsorption of formic acid on reduced and defective rutile $\mathrm{TiO}_{2}$ (110) has been investigated with IRRAS utilizing both s- and p-polarized light incident in the [001] and [1시 crystal directions. Results are compared with DRIFTS of rutile nanoparticles. IRRAS spectra of formic acid adsorbed on $\mathrm{r}-\mathrm{TiO}_{2}$ (110) single crystal surfaces in UHV show larger similarities with DRIFT spectra of formic acid adsorbed on rutile nanocrystals at atmospheric pressures. The main difference is that the nanoparticle samples exhibit a larger amount of formate bonded to hydroxylated oxygen vacancies (or hydroxylated corners and edges) and protonated oxygen atoms than the $\mathrm{r}-\mathrm{TiO}_{2}$ surface. For defective (sputtered) $\mathrm{sp}-\mathrm{TiO}_{2}$ (110) surface the formate adsorption 
geometry is different compared with the $\mathrm{r}-\mathrm{TiO}_{2}(110)$ surface and rutile nanoparticles. On the $\mathrm{sp}-\mathrm{TiO}_{2}$ surface, the orientation of the adsorbed molecules with respect to the surface is lost as there are no differences in the IRRAS spectra for different angles of incidence of the IR light. Only traces of the majority species $\mathrm{A}$, bonded in bridging bidentate adsorption geometry, seen on the $\mathrm{r}-\mathrm{TiO}_{2}$ surface and on nanoparticle, are seen on $\mathrm{sp}-\mathrm{TiO}_{2}$. The changed adsorption geometry of formate for $\mathrm{sp}-\mathrm{TiO}_{2}$ is attributed to a changed surface structure with a surplus of $\mathrm{Ti}^{3+}$ cations due to the preferential sputtering of oxygen atoms.

UV irradiation of formate adsorbate on the $\mathrm{r}-\mathrm{TiO}_{2}$ and sp- $\mathrm{TiO}_{2}$ surfaces under UHV conditions shows a very low photoreaction rate, much lower than previous reports of formate photodecomposition rate on rutile nanoparticles, which itself exhibited a low photodecomposition rate. This can be rationalized by the absence of $\mathrm{O}_{2}$ electron scavenger in UHV and limited supply of surface hydroxyls. It is found that the defective $\mathrm{sp}-\mathrm{TiO}_{2}$ surfaces exhibit a larger photoreactivity compared with $\mathrm{r}-\mathrm{TiO}_{2}$ surfaces, which is explained by changed adsorbate structure, and higher water/hydroxyl surface coverage and oxygen availability on the $\mathrm{sp}-\mathrm{TiO}_{2}$ surface. The results point to a pressure gap between studies conducted under vacuum and those performed under ambient conditions.

\section{ACKNOWLEDGMENTS}

A.M. and L.Ö. thank financial support from The Swedish Research Council (Grant No. VR 2010-3514). K.H. thanks financial support from the VR, eSSENCE, and STINT. This work was also supported by the COST Action CM1104 "Reducible oxide chemistry, structure and functions."

${ }^{1}$ A. Fujishima, X. Zhang, and D. A. Tryk, Surf. Sci. Rep. 63, 515 (2008).

${ }^{2}$ J. Peral, X. Domenech, and D. F. Ollis, J. Chem. Technol. Biotechnol. 70, 117 (1997).

${ }^{3}$ M. R. Hoffmann, S. T. Martin, W. Choi, and D. W. Bahnemann, Chem. Rev. 95, 69 (1995).

${ }^{4}$ A. J. Bard and M. A. Fox, Acc. Chem. Res. 28, 141 (1995).

${ }^{5}$ On Solar Hydrogen \& Nanotechnology, edited by L. Vayssieres (Wiley, Singapore, 2010).

${ }^{6}$ M. G. Walter, E. L. Warren, J. R. McKone, S. W. Boettcher, Q. Mi, E. A. Santori, and N. S. Lewis, Chem. Rev. 110, 6446 (2010).
${ }^{7}$ C.-L. Pang, R. Lindsay, and G. Thornton, Chem. Rev. 113, 3887 (2013).

${ }^{8}$ T. L. Thompson and J. T. Yates, Jr., Chem. Rev. 106, 4428 (2006).

${ }^{9}$ M. A. Henderson, Surf. Sci. Rep. 66, 185 (2011).

${ }^{10}$ U. Diebold, Surf. Sci. Rep. 48, 53 (2003).

${ }^{11}$ Z. Dohnalek, I. Lyubinetsky, and R. Rousseau, Prog. Surf. Sci. 85, 161 (2010).

${ }^{12}$ N. G. Petrik and G. A. Kimmel, J. Phys. Chem. Lett. 3, 3425 (2012).

${ }^{13}$ B. E. Hayden, A. King, and M. A. Newton, J. Phys. Chem. B 103, 203 (1999).

${ }^{14}$ M. Xu, Y. Gao, Y. Wang, and C. Wöll, Phys. Chem. Chem. Phys. 12, 3649 (2010).

${ }^{15}$ A. Mattsson, S.-L. Hu, K. Hermansson, and L. Österlund, J. Chem. Phys. 140, 034705 (2014).

${ }^{16}$ G. A. Kimmel, M. Baer, N. G. Petrik, J. Vandevondele, R. Rousseau, and C. J. Mundy, J. Phys. Chem. Lett. 3, 778 (2012).

${ }^{17}$ H. Noei et al., Phys. Status Solidi B 250, 1204 (2013).

${ }^{18}$ M. Xu, H. Noei, M. Buchholz, M. Muhler, C. Wöll, and Y. Wang, Catal. Today 182, 12 (2012).

${ }^{19}$ V. R. Rai and S. Agarwal, J. Vac. Sci. Technol., A 30, 01 A158 (2012).

${ }^{20}$ Y. J. Chabal, Surf. Sci. Rep. 8, 211 (1988).

${ }^{21}$ S. A. Chambers, M. A. Henderson, and Y. J. Kim, Surf. Rev. Lett. 5, 381 (1998).

${ }^{22}$ F. P. Rotzinger, J. M. Kesselman-Truttman, S. J. Hug, V. Shklover, and M. Grätzel, J. Phys. Chem. B 108, 5004 (2004).

${ }^{23}$ G. Busca, Catal. Today 27, 457 (1996).

${ }^{24}$ S. P. Bates, G. Kresse, and M. J. Gillan, Surf. Sci. 409, 336 (1998).

${ }^{25}$ L. Ojamäe, C. Aulin, H. Pedersen, and P.-O. Käll, J. Colloid Interface Sci. 296, 71 (2006).

${ }^{26}$ M. Aizawa, Y. Morikawa, Y. Namai, H. Morikawa, and Y. Iwasawa, J. Phys. Chem. B 109, 18831 (2005).

${ }^{27}$ S. Wendt et al., Surf. Sci. 598, 226 (2005).

${ }^{28}$ D. Matthey, J. G. Wang, S. Wendt, J. Matthiesen, R. Schaub, E. Laegsgaard, B. Hammer, and F. Besenbacher, Science 315, 1692 (2007).

${ }^{29}$ M. A. Henderson, J. Phys. Chem. B 108, 18932 (2004).

${ }^{30}$ S. Hu, P. A. Bopp, L. Österlund, P. Broqvist, and K. Hermansson, J. Phys. Chem. C 118, 14876 (2014).

${ }^{31}$ Y. Yamaguchi, H. Onishi, and Y. Iwasawa, J. Chem. Soc. Faraday Trans. 91, 1663 (1995).

${ }^{32}$ L.-Q. Wang, K. F. Ferris, A. N. Shultz, D. R. Baer, and M. H. Engelhard, Surf. Sci. 380, 352 (1997).

${ }^{33}$ L. Österlund, Solid State Chemistry and Photocatalysis of Titanium Dioxide, edited by M. K. Nowotny and J. Nowotny (Trans Tech, StafaZürich, Switzerland, 2010), pp. 203-219.

${ }^{34}$ J. E. Bertie, H. J. Labbé, and E. Whalley, J. Chem. Phys. 50, 4501 (1969).

${ }^{35}$ H. Sezen, M. Buchholz, A. Nefedov, C. Natzeck, S. Heissler, C. Di Valentin, and C. Wöll, Sci. Rep. 4, 3808 (2014).

${ }^{36}$ D. S. Muggli and J. L. Falconer, J. Catal. 187, 230 (1999).

${ }^{37}$ D. S. Muggli and J. L. Falconer, J. Catal. 191, 318 (2000).

${ }^{38}$ A. Mattsson, M. Leideborg, L. Persson, G. Westin, and L. Österlund, J. Phys. Chem. C 113, 3810 (2009). 